\title{
MIS CELÁNEA
}

\section{"SACHO $:$ UNA ADAPTACIÓN SEMÁNTICA DEL ANDALUZ EN EL ESPAÑOL DE PUERTO RICO}

0.1. El estudio de cualquier aspecto de la lengua está claro que debe partir de lo que aceptamos como verdad, y la verdad de la lengua bien puede encontrarse en el habla. Quizá por esto una de las más importantes contribuciones de la Geografía Lingüística haya sido, y sea, mostrar esta verdad al ofrecer la lengua viva de una región. En el aspecto que nos ocupa, este método de investigación presenta la distribución diatópica de las unidades recogidas, y la posibilidad de someterlas a cómputos de frecuencias para determinar sus significaciones fundamentales y su estructuración semántica. El estudio del vocabulario recogido en los atlas lingüísticos garantiza así unos resultados confiables.

0.2. La técnica de la encuesta geográfica me permitió recoger en Puerto Rico, en 1980, el término sacho como término del vocabulario marinero dentro del campo léxico «instrumentos para fondear».

Si tenemos en cuenta el significado patrimonial de sacho, instrumento de hierro, con su astil, uno y otro pequeños y manejables, en figura de azadón, que sirve para sachar' (Diccionario de la Real Academia Española, s.v.), no hay duda de que estamos ante un caso de adaptación semántica. Este trabajo se propone dar cuenta de este caso particular del léxico marinero de la Isla.

0.3. Si además partimos de que las hablas meridionales de Espana han ejercido considerable influencia en las hablas del Caribe a través 
de las Islas Canarias, es oportuna y necesaria una exploración en estas áreas dialectales; el estudio de dicho campo léxico en Andalucía y Canarias permite determinar si la adaptación es un fenómeno trasplantado a Puerto Rico o si es un hecho propio de la región. Las tres áreas pueden ser comparadas porque los datos particulares han sido allegados con los mismos métodos y con cuestionarios semejantes. Los resultados finales, por lo tanto, se apoyan en el análisis del campo léxico que nos ocupa en Andalucía, Canarias y Puerto Rico.

1.1. El Atlas lingüístico y etnográfico de Andalucía ${ }^{1}$ dedica los mapas 986-1099 a «Encuestas de mar» en el Tomo IV, y ofrece un inventario riquísimo de unidades léxicas. A lo largo de toda la costa, de Oriente a Occidente, el ALEA muestra 17 puntos visitados, desde Palomares, en Almería, hasta Ayamonte, en Huelva.

El campo léxico «Instrumentos para fondear" queda constituido por las respuestas recogidas en cuatro mapas correspondientes a cuatro sememas:

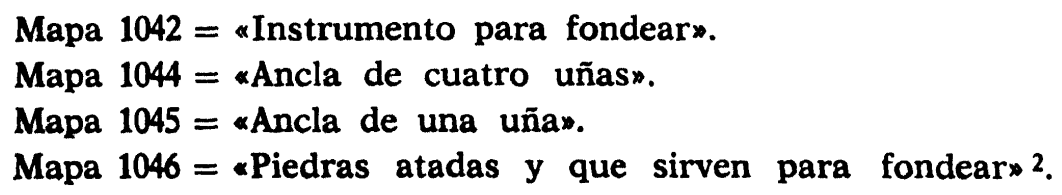

Las unidades documentadas aparecen en el Cuadro I. El signo + registra la presencia de cada unidad en los mapas correspondientes.

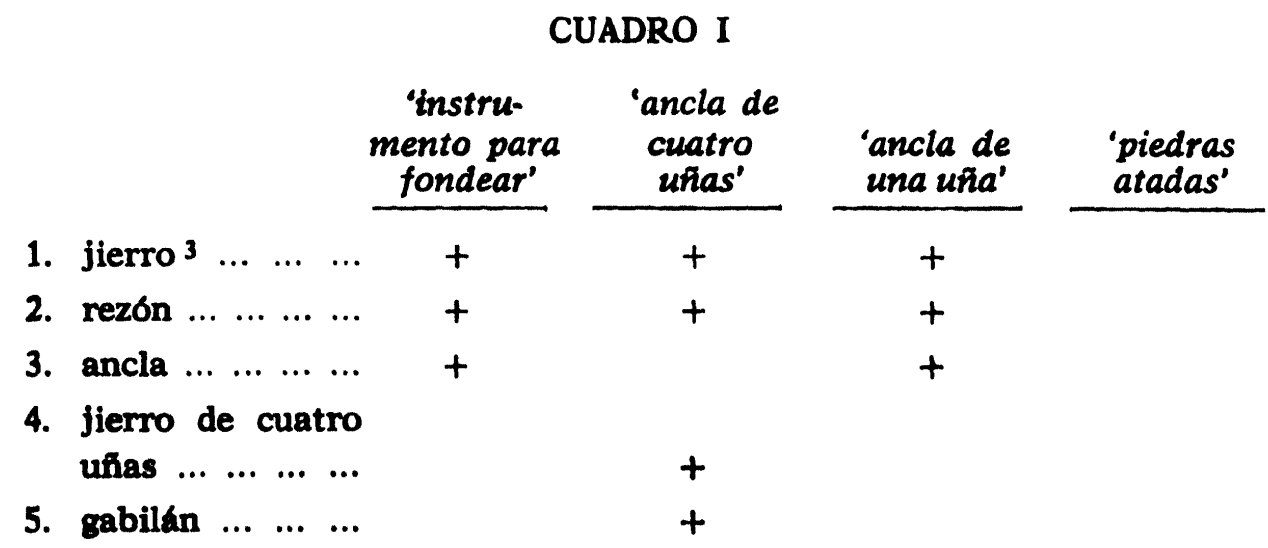

1 alvar, M. (con la colaboración de A. LlorbntB y G. Salvador): Atlas lingülistico $y$ etnogrdfico de Andalucia, Granada, 1961-1973, 6 vols.

2 El mapa 1043 se refiere al semema 'acción de anclar'.

3 Las unidades léxicas recogidas en los inventarios presentan en los mapas variantes fonéticas variadas. Se escogí la variante más general: jierro incluye yerro y otras con distinto grado de aspiración inicial; rezón incluye reson; pedral incluye pedrala. 


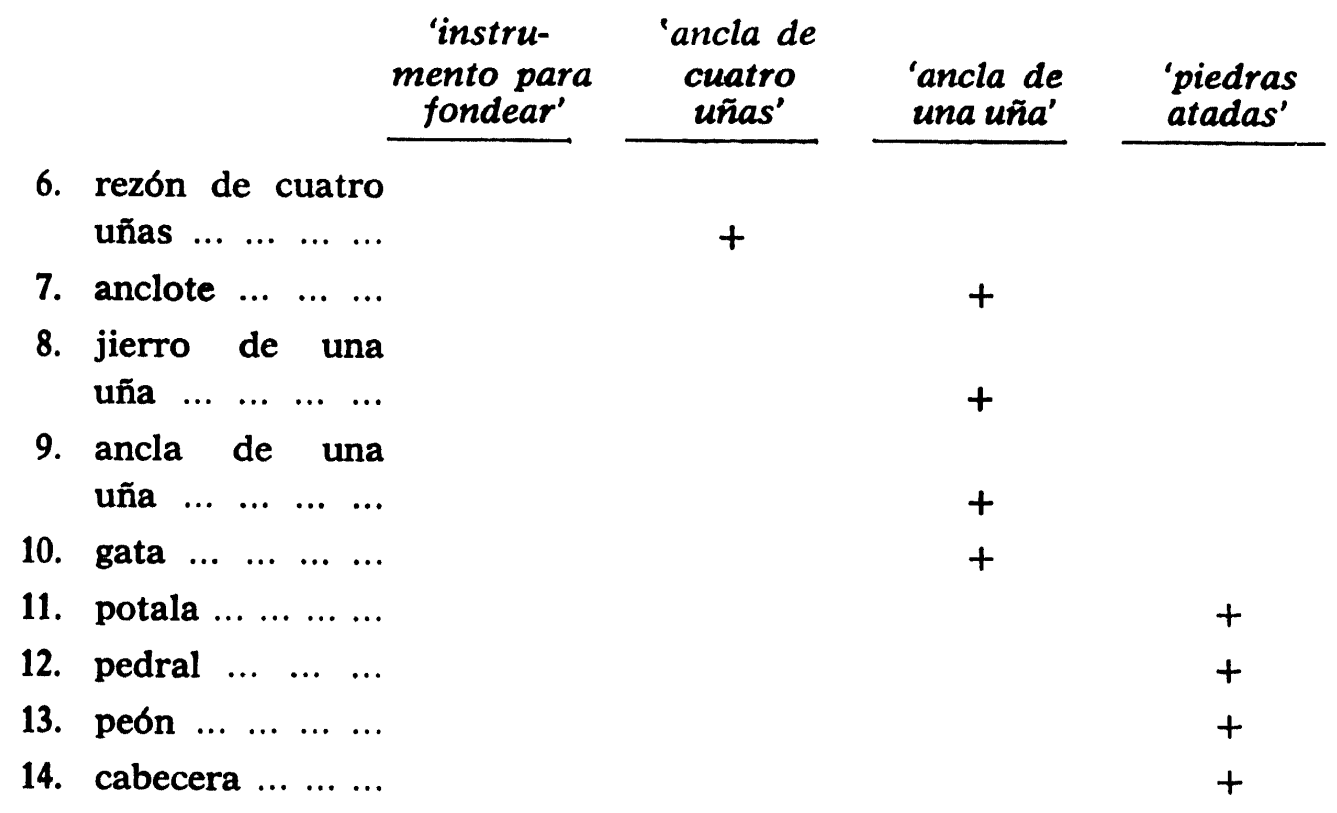

La observación del Cuadro I permite establecer una clarísima diferencia entre las anclas propiamente dichas y las piedras atadas que se usan para fondear, nunca designadas con los términos jierro, rezón, ancla $^{4}$, que podríamos llamar archilexemas para los tres primeros sememas. Los hablantes oponen así lingüísticamente los dos tipos de instrumentos. Y si tenemos en cuenta que de los cuatro vocablos exclusivos para el segundo tipo ('piedras atadas'), el más general es potala documentado en 12 puntos $(70,5 \%)$, el vocabulario relativo a los instrumentos para fondear en el $A L E A$ presenta una primera oposición:

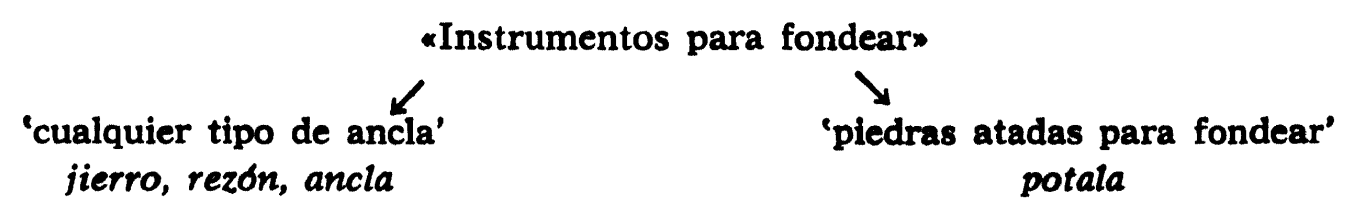

Aclarada su función, prescindimos del mapa 1046 y de los cuatro términos exclusivos correspondientes, de los cuales pedral, peón y cabecera tienen escasísima vitalidad, todos en la costa oriental, y son de fácil explicación. A continuación aparecen los datos relativos a frecuencia y distribución geográfica de las unidades recogidas en los tres primeros mapas.

\footnotetext{
4 Aunque ancla no está presente en el segundo mapa, 'ancla de cuatro uñas', la colocamos en el mismo rango de rezón, que sólo tiene una aparición en el primer mapa, 'instrumento para fondear' (véase Cuadro II). Colocarla en el mismo rango general, no quiere decir que tenga el mismo valor.

5 Potala: voz formada probablemente sobre potar 'contrastar', 'pesar' (Garch DR Drego, Diccionario Etimológico, núm. 4732).
} 
CUADRO II

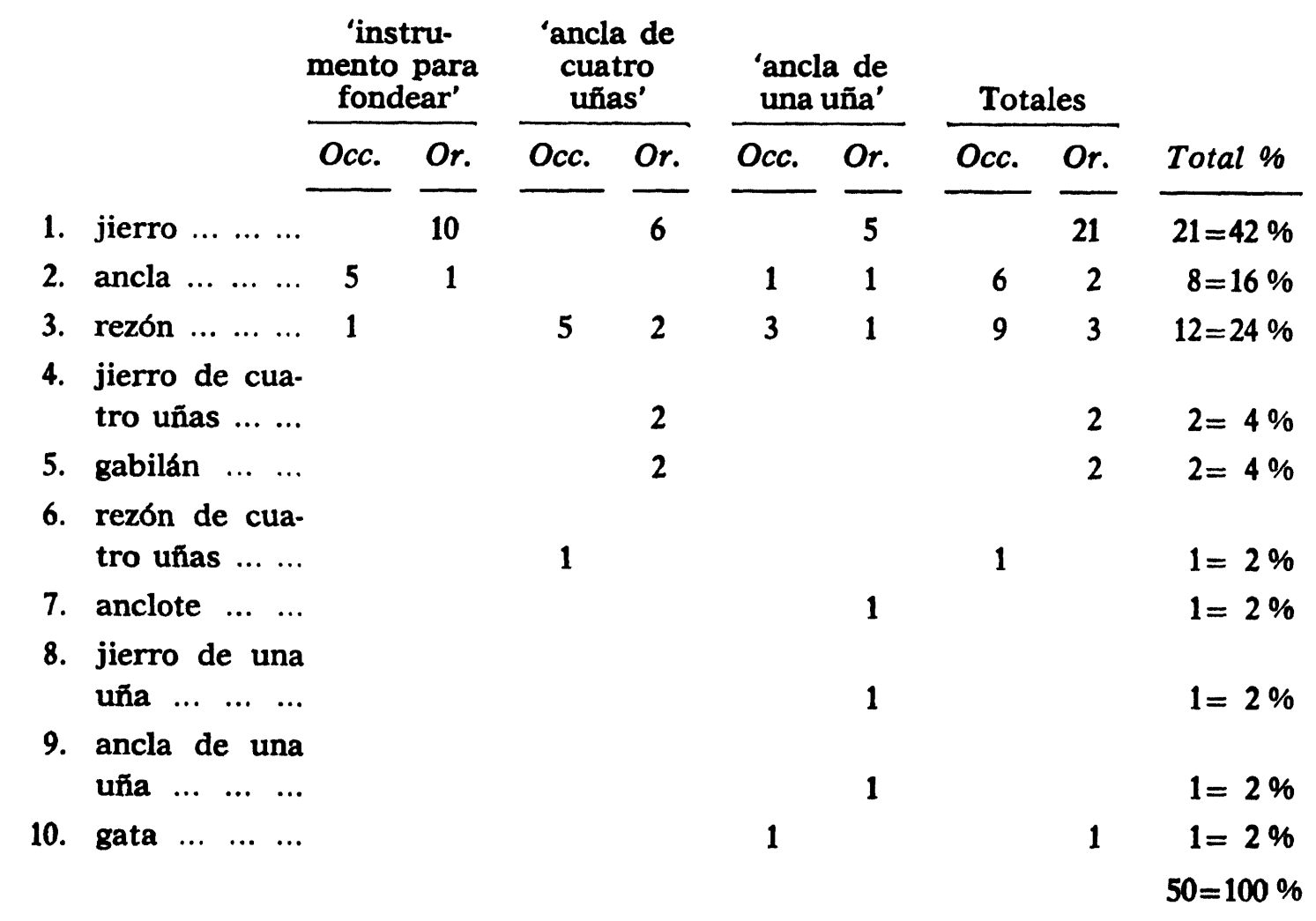

1.2. Jierro y rezón pueden designar los tres sememas, pero los datos allegados exigen hacer algunas precisiones importantes:

1.2.1. Jierro es el vocablo que ofrece más frecuencia general de uso, con 21 apariciones $(42 \%)$, de las cuales, $10(47,61 \%)$ se refieren al semema 'instrumento para fondear', que puede entonces considerarse su «significación fundamental». Tiene además este término una distribución geográfica precisa: aparece exclusivamente en la costa oriental.

1.2.2. Rezón es el segundo vocablo en frecuencia general, con 12 apariciones $(24 \%)$. Si tenemos en cuenta que siete apariciones designan 'ancla de cuatro uñas' $(58,3 \%)$, ésta será su «significación fundamental». Aunque no es forma exclusiva de una región determinada, es más frecuente en la costa occidental, con nueve casos (75\%).

1.2.3. Ancla no presenta el mismo poder de «recubrimiento" (no se documenta en el segundo mapa) ${ }^{6}$ y su frecuencia general es considera-

6 «Poder de recubrimiento y/o "valencia léxican: sigo a JEAN-GuY SAVARD, La valence lexicale, Centre International de Recherches sur le bilinguisme, Université Laval Québec, Didier, 1970. 
blemente más baja: ocho apariciones (16\%). La «significación fundamental» es 'instrumento para fondear', con seis apariciones $(75 \%)$, y además es palabra localizada sobre todo en Occidente (75\%).

1.2.4. Lo dicho puede presentarse en el Cuadro III:

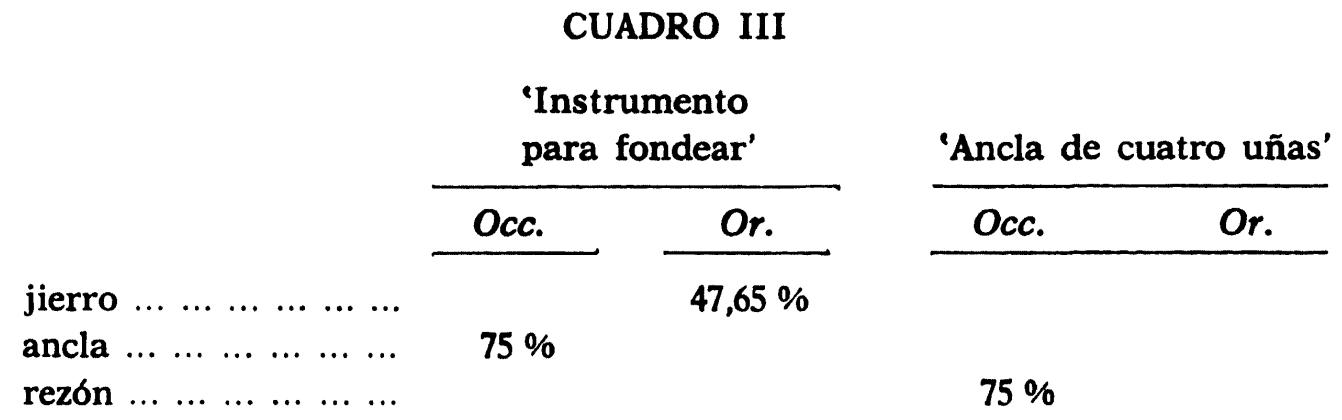

A partir de estos datos podemos descubrir el valor de estas unidades.

1.2.4.1. Jierro y ancla se oponen a rezón por su «significación fundamental»:

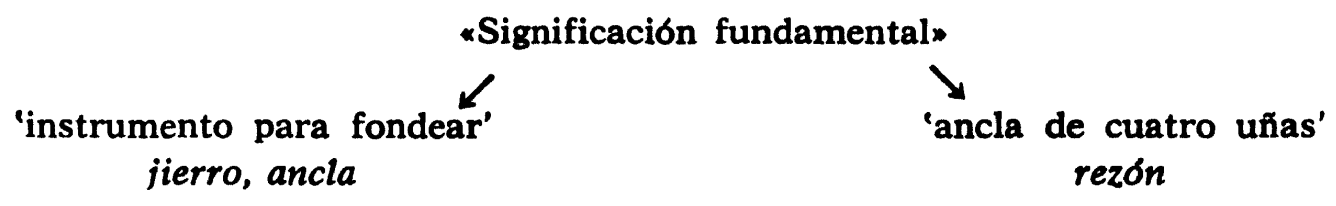

1.2.4.2. A su vez jierro se opone a ancla por su distribución geográfica:

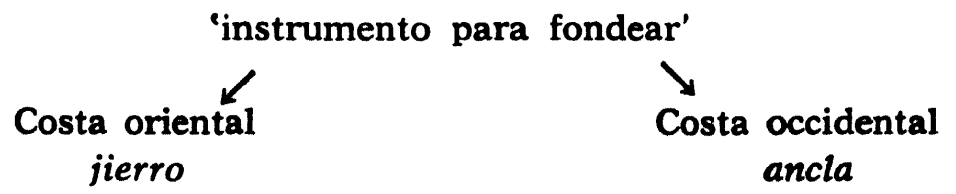

1.2.4.3. Desde el punto de vista de la frecuencia y del «poder de recubrimienton, jierro es el vocablo que puede considerarse archilexema por designar cualquier instrumento para fondear que no sea potala. Esto quiere decir, por una parte, que el significado de jierro es más amplio que el de ancla, y por otra se puede observar el avance de la forma andaluza jierro frente a la castellana ancla.

1.2.4.4. Jierro es archilexema y puede designar 'ancla de cuatro unas' y 'ancla de una uña'; cuando esto sucede, siempre en Oriente, dichos sememas se designan rezón en Occidente.

1.2.4.5. Aunque muy poco frecuentes, son interesantes las adaptaciones basadas en atributos o cualidades de ciertos animales, caracteri- 
zados por su acción de «arañar». Dos términos se oponen semánticamente, respondiendo a este tipo de adaptaciones:

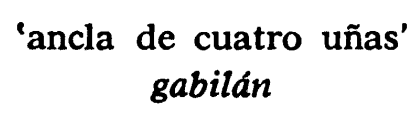

2.1. El Atlas lingüístico-etnográfico de las Islas Canarias ${ }^{7}$ ofrece el vocabulario correspondiente al campo que estudiamos en el mapa 828 (Tomo III), dedicado al semema 'ancla', y en el mapa 831, donde se documenta el término potala en todos los puntos, salvo en tres de Tenerife donde la llaman pandulo.

El vocabulario recogido en Canarias para este campo léxico aparece a continuación, en el Cuadro IV.

\begin{tabular}{|c|c|c|c|c|}
\hline \multicolumn{5}{|c|}{ CUADRO IV } \\
\hline & $\begin{array}{l}\text { 'instru- } \\
\text { mento para } \\
\text { fondear' }\end{array}$ & $\begin{array}{c}\text { 'ancla de } \\
\text { cuatro } \\
\text { uñas' }\end{array}$ & $\begin{array}{l}\text { 'ancla de } \\
\text { una uña' }\end{array}$ & $\begin{array}{l}\text { 'piedras } \\
\text { atadas' }\end{array}$ \\
\hline 1. ancla $\ldots \ldots \ldots \ldots$ & + & + & & \\
\hline 2. $\operatorname{ros} 6 n \ldots \ldots$ & + & + & & \\
\hline 3. $\operatorname{rosiega} \ldots \ldots \ldots$ & & + & & \\
\hline 4. anclote $\ldots \ldots \ldots$ & + & & + & \\
\hline 5. $\begin{array}{cccc}\text { potala } & \ldots & \ldots & \ldots\end{array}$ & & & & + \\
\hline 6. pandulo ... ...... & & & & + \\
\hline
\end{tabular}

Como en Andalucía, los hablantes canarios distinguen los dos tipos de instrumentos para fondear, y los oponen lingüísticamente mediante las siguientes unidades:

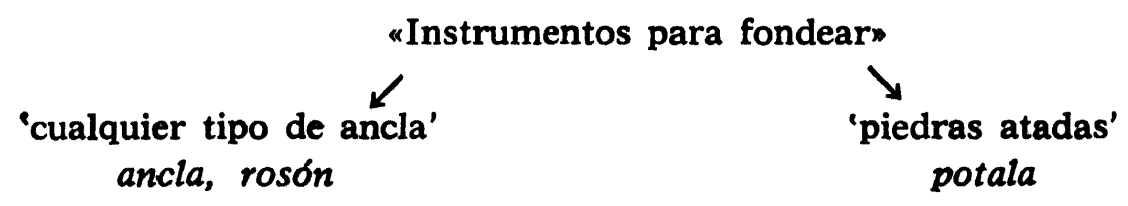

2.2. Prescindiendo de los dos vocablos recogidos para piedras atadas', de los cuales el general es, como en Andalucía, potala, la frecuencia y distribución de los vocablos restantes aparece en los cuadros siguientes $V(a)$ y $V(b)$ :

7 Alvar, M., ALEICan, Ediciones del Excmo. Cabildo Insular de Gran Canaria, 1978, 3 vols. 
CUADRO V(a)

\begin{tabular}{lllllllllllllllll}
\multicolumn{1}{c}{ 'ancla' } & 'ancla de cuatro uñas' \\
LP & $H$ & $G$ & $T f$ & $G C$ & $F v$ & $L$ & Tot. & LP & $H$ & $G$ & Tf & $G C$ & $F v$ & $L$ & $T o t$.
\end{tabular}

1. ancla $\ldots \begin{array}{lllllllll}\ldots & 2 & 2 & 3 & 5 & 3 & 2 & 17\end{array}$

2. rosón $\begin{array}{lllllllllll} & \ldots & 1 & 1 & 2 & 1 & 3 & 8\end{array}$

3. rosiega . ...

$1 \quad 1 \quad 2$

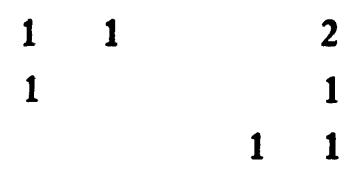

4. anclote ...

'ancla de una uña'

1. ancla ......

$\begin{array}{llllllll}L P & H & G & \text { Tf } & G C & F v & L & T o t\end{array}$

2. roson .......

3. rosiega ....

4. anclote....

1

1

CUADRO V(b)

\begin{tabular}{|c|c|c|}
\hline & Totales & Frecuencias \\
\hline $\begin{array}{lllllllll}\text { 1. } & \text { ancla } & \ldots & \ldots & \ldots & \ldots & \ldots & \ldots & \ldots\end{array}$ & 17 & $51,52 \%$ \\
\hline 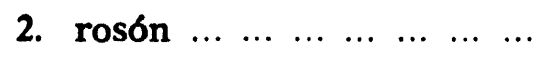 & 11 & $33,33 \%$ \\
\hline 3. $\begin{array}{rrrrrrr}r o s i e g a & \ldots & \ldots & \ldots & \ldots & \ldots & \ldots\end{array}$ & 1 & $3,03 \%$ \\
\hline 4. $\begin{array}{llllllll} & \text { anclote } & \ldots & \ldots & \ldots & \ldots & \ldots & \ldots\end{array}$ & 4 & $12,12 \%$ \\
\hline GRAN TOTAL $\ldots . . . .$. & 33 & $100 \%$ \\
\hline
\end{tabular}

2.3. Las cuatro unidades léxicas recogidas en las Islas Canarias, ancla, rosón, rosiega y anclote, frente a las diez andaluzas, corroboran una vez más lo que ya se ha destacado de las Islas: su mayor uniformidad linguística 8 , por un lado, y por otro su mayor homogeneidad geográfica, puesto que no es fácil trazar áreas lingüísticas definidas.

8 Sobre este aspecto ha escrito páginas definitivas ManuEr ALvar; véase su trabajo *Originalidad interna en el léxico canario», I Simposio internacional de lengua espariola, Ediciones del Excmo. Cabildo Insular de Gran Canaria, 1981, págs. 225-272. Ha corroborado estas caracteristicas canarias Jurro Fernánez SEvinL, desde el estudio del vocabulario agricola: «Andalucía y Canarias: relaciones léxicas», ibid., página 74. También ISABEL DELGADO DE LABORDE, Estudio léxico de los arabismos en el español de las Islas Canarias, Tesis doctoral inédita, Departamento de Estudios Hispánicos, Universidad de Puerto Rico, 1982. 
2.4. Las abundantes anotaciones y los diacríticos que aparecen en el mapa 828 del ALEICan permiten deducir que en las Islas las respuestas no son tan seguras como en Andalucía, por desconocimiento del objeto o por desuso, lo cual explica la intervención de un segundo o tercer informante en la encuesta, y la frecuencia de las palabras ancla y rosón con significación, exclusiva y casi exclusiva respectivamente, de 'ancla' ('instrumento para fondear', general).

2.5. El término rosón de Canarias no debe considerarse mera variante del resón andaluz, cuya significación fundamental es 'ancla de cuatro uñas'. En las Islas rosón compite con ancla como término para designar 'ancla', y esta significación representa el $72,73 \%$, con lo cual el valor de ancla es, además, distinto en las dos áreas.

El criterio de "significación fundamental» no puede determinar, o suponer, que se trata de dos vocablos diferentes; además sabemos que dos áreas dialectales no sólo pueden distinguirse por el uso de variantes léxicas y/o fonéticas, sino por el distinto valor semántico de cada una dentro de cada área. De ahí la importancia de los cómputos de frecuencia, generales, y particulares para cada significación.

En el caso que nos ocupa, la forma canaria rosón puede ser resultado de una adaptación del castellano rozón, 'especie de guadaña tosca, gruesa y ancha, que sujeta a un mango largo, sirve para rozar árgoma, zarzas, etc.' (DRAE, s. v.).

El hecho de que no aparezca en el $A L E A$ la palabra rosón, ni en el vocabulario marinero (donde lo que encontramos es resón y rezón), ni en el vocabulario agrícola, hace suponer que esta forma no vive en Andalucía. Asimismo, su presencia en Canarias puede deberse a una adaptación castellana del léxico agrícola al léxico marinero de las Islas. Por otra parte, no está documentada la voz entre las recogidas en Canarias para los instrumentos del campo.

Esto no quiere decir que no haya habido en Canarias un posible cruce entre rosón (castellano adaptado) y resón, perfectamente explicable por la similitud fonética. La presencia, escasísima, de la forma resón en Canarias para 'ancla' podría ser producto de este cruce.

Los datos allegados por el ALEICan hacen suponer, si están bien interpretadas las respuestas de los mapas, que con el término ancla se designa 'ancla' y que con rosón se designa 'ancla' en un $72,73 \%(27,27 \%$ corresponde a 'ancla de cuatro uńas'). Asimismo, que el 'ancla de cuatro uñas' puede designarse con los términos rosón, rosiega y anclote, y que rosón y anclote pueden designar 'ancla de una uña'. 
2.6. Tanto en Canarias como en Andalucía el término ancla recoge la significación general 'ancla' (75\% en Andalucía, $100 \%$ en Canarias), pero la diferencia está en las frecuencias de uso: ancla tiene en Andalucía una frecuencia de uso del $16 \%$, mientras que en Canarias tiene el $51,22 \%$. De esto se deduce que la palabra es más frecuente en Canarias, y que en Andalucía, si bien conserva su valor semántico, cede terreno a la forma local jierro, que además adquiere valor geográfico, como se vio más arriba. Por su parte, jierro es andalucismo que no está documentado en Canarias.

2.7. Anclote puede designar en Canarias tanto 'ancla' (50\%), como 'ancla de cuatro uñas' (25\%), como 'ancla de una uña' (25\%), con lo cual se destaca el distinto valor de esta voz en las dos áreas, puesto que en Andalucía anclote sólo designa 'ancla de una uña' (100\%).

2.8. Gabilán y gata no aparecen en Canarias, como tampoco aparecen las lexías. En cambio es propio de Canarias el vocablo rosiega para 'ancla de cuatro uñas', de escasísima vitalidad (3,03\%), localizado en Tenerife.

Según la documentación de García de Diego (Diccionario, núm. 5742), esta palabra puede relacionarse con rocegar (< *rosicare 'roer', 'rozar'), 'rozar en el suelo' ant. castellano, y aragonés; rosegar, 'roer' arag., 'rozar' murciano. No hay duda de que rosiega está relacionado con las formas aducidas por de Diego; lo que no está tan clara es la presencia del término en Canarias.

Teniendo en cuenta los derivados en portugués que este mismo lexicógrafo aduce, rosiega puede ser un portuguesismo en Canarias, más que un término del Oriente peninsular, a juzgar por la influencia del portugués en las Islas. Pero este punto necesitaría más documentación.

3.1. No tiene Puerto Rico un atlas cuyos datos podamos comparar con los de Andalucía y Canarias, por varias razones. El atlas de que disponemos se remonta al año 1927 en la recogida de materiales ${ }^{9}$, y además su vocabulario es sobre todo campesino. Para cualquier estudio y comparación posterior hay que recoger el léxico que se quiera estudiar, en espera del Atlas lingüístico de América, proyecto actualmente en marcha.

Recoger el vocabulario marinero de Puerto Rico fue el propósito de una serie de encuestas que realicé en 1980 , en 12 puntos de la costa de

9 Nhvarro Tomas, T., El español en Puerto Rico, Editorial Universitaria, 1948. 
la Isla ${ }^{10}$. El cuestionario utilizado, de 83 preguntas, partió de los mapas dedicados a "encuestas de mar" en el $A L E A$ y en el $A L E I C a n$, lo cual permite las comparaciones correspondientes.

Respecto al campo léxico «instrumentos para fondear», se recogieron en Puerto Rico los siguientes vocablos:

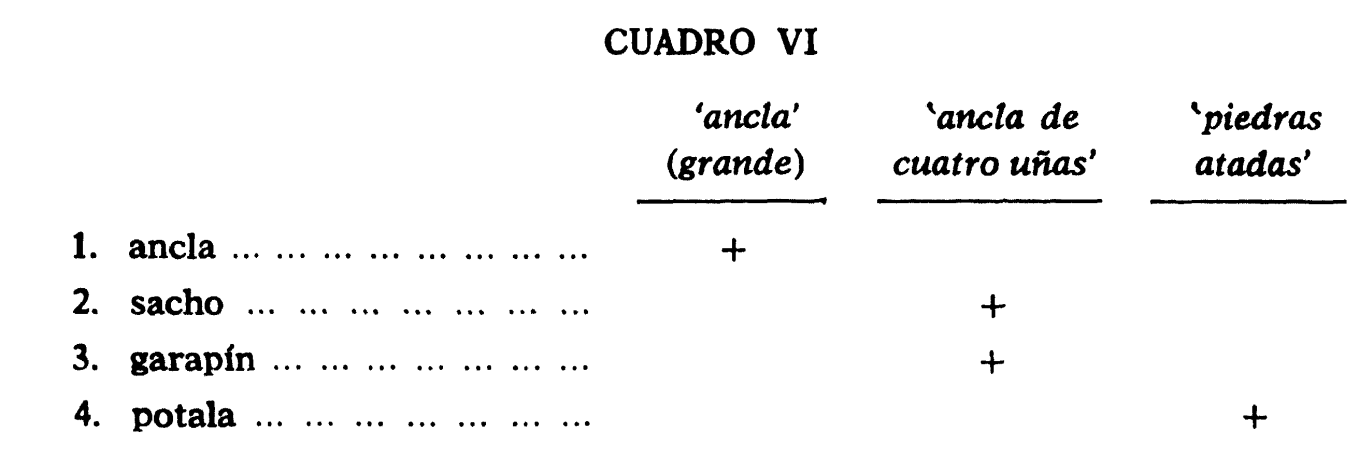

3.2. En Puerto Rico existen claramente diferenciados tres tipos de instrumentos para fondear, con lexemas exclusivos para cada tipo.

3.2.1. Semema 'ancla', cuyos semas son:

instrumento para fondear

de los barcos grandes, o buques

de dos uñas

de fabricación industrial

El lexema correspondiente es ancla.

3.2.2. Semema 'ancla de cuatro uñas', cuyos semas son:

$$
\begin{aligned}
& \text { instrumento para fondear } \\
& \text { de las embarcaciones pequeñas } \\
& \text { de cuatro uñas } \\
& \text { de fabricación casera }
\end{aligned}
$$

Los lexemas correspondientes son sacho y garapin.

3.2.3. Semema 'piedras atadas', que se opone a los anteriores, como en Canarias y Andalucía, y que recibe la denominación de potala.

3.3. Si tenemos en cuenta que ancla no forma parte del vocabulario habitual del pescador puertorriqueño, y que potala es el lexema para

10 Vaquero, M., «Léxico marinero de Puerto Rico», II Simposio internacional de lengua española, Ediciones del Excmo. Cabildo Insular de Gran Canaria, 1984, páginas $301-423$. 
'piedras atadas', el campo se organiza internamente en las siguientes oposiciones:

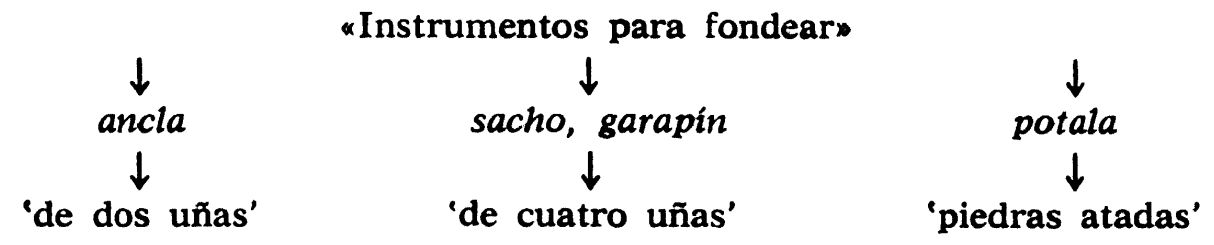

3.4. Sacho y garapin se oponen en la Isla geográficamente:

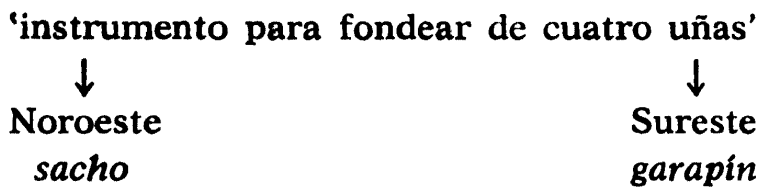

3.5. Si comparamos estos datos con los anteriores podemos observar lo siguiente:

3.5.1. La palabra patrimonial ancla ha ido retirándose del vocabulario habitual del pescador de Puerto Rico, destinada a un referente ajeno a su circunstancia: sus embarcaciones son pequeñas. En su lugar, utiliza un objeto de fabricación doméstica, siempre de cuatro uñas, que no se designa con las palabras que podíamos esperar, resón, rosón, etc., sino con unas voces que son tan locales como el objeto mismo, producto de adaptación. De esta manera, el campo que estudiamos ofrece en Puerto Rico un inventario de formas que, además de ser más reducido, es producto de adaptaciones propias, y donde el valor del término ancla es diferente de los anteriores.

$\mathrm{Y}$ nos encontramos ante dos términos del léxico marinero de Puerto Rico que, al no pertenecer al léxico marinero de Andalucía o Canarias, hay que explicar siguiendo otros caminos.

4.1. En el $A L E A$, sacho designa un tipo de herramienta agrícola, a la cual dedica Julio Fernández Sevilla todas las observaciones que se le pueden hacer ${ }^{11}$. Según los datos ofrecidos por este investigador, el sacho andaluz es uno de los seis tipos de escardillo ('herramienta ligera, manejable, con pala de hierro generalmente en punta y mango de madera, que sirve para escardar'). El tipo de escardillo designado sacho responde a las siguientes características: 'zapapico con palas enfrentadas, una de las cuales termina en punta; tiene mango de madera in-

11 Fernandez Sevilla, Julio, Formas y estructuras en el léxico agricola andaluz, C.S.I.C., 1975, pázs. 108, 316, 317, 447, 449. 
crustado en un agujero central'. Aparece en el área occidental, provincia de Huelva, y no puede considerarse sinónimo de escardillo, pues ambos denominan herramientas diferentes.

Por otra parte la denominación andaluza no contradice la definición del término sacho en castellano, 'instrumento de hierro, con su astil, uno y otro pequeños y manejables, en figura de azadón, que sirve para sachar'. Fernández Sevilla, a quien voy siguiendo, le da origen occidental peninsular a esta palabra (Asturias, Galicia y Portugal), donde vive el verbo sachar, sallar 'remover la tierra para sacar las malas hierbas de los sembrados' ${ }^{2}$. Hasta aquí los datos del ALEA.

4.2. En las Islas Canarias el término sacho pertenece también al léxico agrícola y designa un tipo de azada no grande, de una sola pala, plana, con un agujero por donde pasa el mango. Los mapas 17 y 18 del ALEICan muestran la distribución geográfica y las características etnográficas de dicha herramienta. Todo esto permite deducir que en Canarias el vocablo ha experimentado un leve desplazamiento semántico hacia 'azada', con un índice de frecuencia del $36 \%{ }^{13}$. Este desplazamiento se ha realizado de lo particular (tipo de azada) a lo general (azada).

4.3. El término sacho recogido en Puerto Rico como variante léxica del área noroccidental, es una adaptación local; designa el instrumento, también local, 'tubo relleno de cemento, donde se insertan cuatro varillas de hierro a manera de ganchos', según las explicaciones de mis pescadores, y el objeto mismo ${ }^{14}$.

12 Para la variante sallar, GeRHARD RoHLF, Estudios sobre el léxico románico, reelaboración parcial y notas de Manuel Alvar, Madrid, Gredos, 1979, núm. 96, nota 410.

13 Fernandez Sevilla, Julio, «Relaciones léxicas», pág. 83.

14 Alvarez Nazario, M., La herencia linguística de Canarias en Puerto Rico, Instituto de Cultura Puertorriquefía, San Juan de Puerto Rico, 1972, núm. 239 (c). Se refiere este investigador puertorriqueño al uso del sacho entre pescadores de la Isla, basándose en los datos allegados por monografías sobre regiones del país: Engracia Cerrzo DE PonCe, La zona lingüística de Aguadilla, Tesis doctoral inédita, Departamento de Estudios Hispánicos, Universidad de Puerto Rico, 1966, y EDWIN Figurron Berrofos, Habla y folklore de Ponce, Tesis doctoral inédita, Universidad Complutense de Madrid, 1965. Alvarez Nazario recuerda la adaptación paralela ocurrida en el archipiélago de Chiloé, siguiendo a F. J. Santamarta, si bien el objeto que describe este lexicógrafo en su Diccionario general de americanismos, 'armazón de madera con lastre de piedras, usada por las embarcaciones pequeñas' (s. v. sacho), no es el mismo objeto que se usa en Puerto Rico. El diccionario académico, por su parte, recoge esta adaptación chilena (s. v. sacho, segunda acepción). 
No hay duda de que la semejanza entre la herramienta y el objeto marinero es evidente: por un lado el tamaño del sacho agrícola, pequeño y manejable, y por otro, su función principal de escarbar la tierra, permiten que el vocablo se haya desplazado para designar el objeto que escarba la arena para anclar en el mar.

4.3.1. La acción de anclar no se denomina con el verbo sachar, sino que el lexema habitual en Puerto Rico es fondear (documentado en nueve puntos), al lado de apotalar. (Aparecen lexías del tipo tirar el sacho.)

El nombre del objeto y la acción correspondiente van por caminos separados y en esto Puerto Rico coincide con Canarias, puesto que en ambas áreas dialectales distintos factores han condicionado el desarrollo de adaptaciones propias, y las palabras han seguido cursos separados; un mismo campo léxico posee unidades de distintos troncos porque los desplazamientos semánticos se pueden producir en una sola unidad del campo, sin que arrastre hacia el tronco nuevo a las demás unidades. En Puerto Rico tenemos sacho, pero fondear o apotalar. Esto prueba la variedad de factores que conforman el léxico de las hablas trasplantadas, como son la de Canarias o las de América, hablas, por lo mismo, llenas de sorpresas dentro de su marcada homogeneidad regional.

5.1. No encuentro documentado el término garapín en ninguno de los estudios y diccionarios que manejo, ni tampoco pertenece al léxico marinero andaluz o canario. Si lo relacionamos con garabin, bien puede tratarse de otra adaptación agrícola del andaluz en Puerto Rico, no documentada antes.

En el mapa 145 del $A L E A$ se recoge en garabi(ses) en Córdoba, para designar las orejeras del arado, 'cada una de las piezas o palos que el arado común lleva introducidos oblicuamente a uno y otro lado del dental y que sirven para ensanchar el surco' (DRALE, s. v. orejera, 3." acepción).

5.2. Partiendo de las láminas etnográficas 133 y 134 del $A L E A$, las orejeras funcionan a manera de ganchos de separación al arrastrar la tierra a ambos lados del surco, lo cual podría justificar el origen que atribuye Fernández Sevilla a la forma cordobesa garabi, relacionada para este autor con garabato 'gancho', perteneciente a la familia prerromana carba 'rama', 'matorral', que dio en asturiano gárabu 'rama delgada separada del árbol', gáraba 'palito', a la que pertenecen también el portugués y leonés carvalho 'roble' ${ }^{15}$.

15 FrRnandez Sevilla, Julio, Formas y estructuras, pág. 423. 
5.3. Tendríamos entonces que el objeto para fondear que usan los pescadores en Puerto Rico, de fabricación casera, se denomina con dos términos del léxico agrícola, de los cuales garabí es andaluz, no canario.

6.1. El estudio de esta pequeña parcela del léxico corrobora que, frente al polimorfismo andaluz, y a la posibilidad de establecer áreas lingüísticas en el Sur de España, las Canarias presentan mayor uniformidad y homogeneidad lingüísticas.

6.2. Puerto Rico es fiel a Andalucía y a Canarias, dentro de su particular manera americana de adaptar la lengua: por un lado presenta, como Canarias, menos variantes léxicas que Andalucía, y con Andalucía distribuye geográficamente algunas de ellas en zonas precisas. Con Canarias, el campo léxico estudiado acoge unidades de distintos troncos léxicos, evidencia de ser, ambas, regiones de adaptación más acusadas que el Sur de España. De Andalucía, sin embargo, parten las adaptaciones, en un proceso del que no se puede excluir el camino de las Islas, primer lugar de desplazamientos semánticos.

6.3. Las particularidades locales alcanzan su dimensión verdadera, no en los inventarios o nóminas, por exhaustivos que sean, sino en la especial estructuración y valor semántico que adquieren dichas unidades entre sí, teniendo en cuenta las significaciones fundamentales o secundarias, las frecuencias de uso general y particular, las distribuciones diatópicas, etc., sin perder de vista, además, que una zona dialectal no está sola, sino que es una parcela dentro del sistema general, y sus particularidades sólo se explican satisfactoriamente si se tienen en cuenta las particularidades de las demás, en un intento de descubrir procesos y mecanismos generales que permitan explicar lo absolutamente exclusivo.

6.4. El lento pero seguro camino recorrido por la lengua española hacia América, nos ofrece la posibilidad de estudiar procesos de expansión y adaptación que den cuenta de particularidades regionales dentro de la unidad de la lengua; particularidades que, si no es posible explicar al margen de lo común, nunca podrán sernos ajenas.

Marfa Vaqubro

Instituto de Lingüistica Universidad de Puerto Rico 